\title{
Estrogen Down-regulator Fulvestrant Potentiates Antitumor Activity of Fluoropyrimidine in Estrogen-responsive MCF-7 Human Breast Cancer Cells
}

\author{
MAMORU NUKATSUKA ${ }^{1}$, HITOSHI SAITO $^{2}$, SHINZABURO NOGUCHI $^{3}$ and TEIJI TAKECHI ${ }^{1}$ \\ ${ }^{1}$ Translational Research Laboratory, Taiho Pharmaceutical Co., Ltd., Tokushima, Japan; \\ ${ }^{2}$ Pharmacology Laboratory, Taiho Pharmaceutical Co., Ltd., Tokushima, Japan; \\ ${ }^{3}$ Department of Breast and Endocrine Surgery, Osaka University Graduate School of Medicine, Osaka, Japan
}

\begin{abstract}
Background: Endocrine therapy is clinically administered in hormone-responsive breast cancer. Combinations of fluoropyrimidine $S-1$ and an aromatase inhibitor or anti-estrogen are considered beneficial in Japan. Herein we assessed new combinations of S-1 and fulvestrant. Patients and Methods: Cytotoxicity of fulvestrant and 5-fluorouracil (5-FU) was assessed in hormone-responsive (MCF-7) and non-responsive (MDA-MB-231) breast cancer cell cultures. Fulvestrant and $S-1$ were evaluated for antitumor activity in mice and their effects on estrogen receptor (ER)- $\alpha$ and progesterone receptor $(P g R)$ levels in MCF-7 xenografts using immunohistochemical methods. Results: Fulvestrant inhibited growth of MCF-7, but not of MDA-MB-231 xenografts. Combinations of 5-FU and fulvestrant were superior to monotherapy in vitro. In vivo antitumor activity of $S$-1/fulvestrant combination therapy was significantly $(p<0.05)$ enhanced compared to that of both monotherapies. Fulvestrant partially down-regulated expression of ER $\alpha$ and $P g R$, but in combination with $S-1$, it almost completely blocked their expression. Conclusion: Chemo-endocrine combination therapy using $S-1$ and fulvestrant is beneficial in estrogen-responsive breast cancer.
\end{abstract}

Breast cancer is the most common cancer in women around the world, including in the United States $(1,2)$ and Japan,

This article is freely accessible online.

Correspondence to: Mamoru Nukatsuka Ph.D., 224-2, Ebisuno Hiraishi, Kawauchi-Cho Tokushima-Shi, Tokushima 771-0194, Japan. Tel: +81 886655337, Fax: +81 886655296, e-mail: m-nukatsuka@taiho.co.jp

Kew Words: Breast cancer, endocrine therapy, chemotherapy, progesterone receptor, estrogen receptor, S-1, fulvestrant, chemoendocrine combination therapy. where it remains the fifth-leading cause of cancer-related death (3). Endocrine therapy is a well-established first-line treatment for estrogen receptor (ER)- $\alpha$-positive, metastatic breast cancer (4). Current endocrine therapy treatment options for menopausal patients with hormone-responsive breast cancer include selective $\mathrm{ER} \alpha$ modulators (e.g. tamoxifen), aromatase inhibitors (e.g. anastrozole, letrozole, and exemestane), and, in addition, selective ER $\alpha$ downregulators (e.g. fulvestrant). An evaluation of several clinical trials of combination therapies testing fulvestrant with cyclin-dependent kinase 4 and 6 inhibitors [PALOMA-3 (5), MONALEESA-3 (6), and MONARCH2 (7)] or phosphoinositide 3-kinase inhibitors [FERG1 (8), BELLE-2 (9), BELLE-3 (10)] indicated that combination with the cyclin-dependent kinase 4 and 6 inhibitor palbociclib was associated with a significantly extended progression-free survival as compared with that of fulvestrant monotherapy. According to the guideline from the European Society for Medical Oncology, antagonistic interactions are predicted to occur using concomitant combination therapy of endocrine therapy and chemotherapy, and, therefore, simultaneous chemo-endocrine therapy is not recommended (11).

However, in contrast to other chemotherapeutic agents, clinical trials in Japan showed that only tegafur (a masked 5-FU derivative)/uracil (UFT), an oral fluoropyrimidine, used in combination with tamoxifen, improved overall survival, compared to surgery alone $(12,13)$. Furthermore, there was no significant difference in relapse-free survival between those treated with UFT therapy and cyclophosphamide/methotrexate/ 5-fluorouracil (5-FU) therapy $(14,15)$. We attempted to confirm the conclusions of this clinical trial. In vitro studies on ER-positive human breast cancer cell lines KPL-1 and ML-20 showed that 4-OH-tamoxifen exerted synergistic inhibitory effects with 5-FU but not with doxorubicin or paclitaxel (16). Furthermore, in vitro growth inhibition by 5 -FU was assessed in the presence and absence of $17 \beta$-estradiol $\left(\mathrm{E}_{2}\right)$. Growth of KPL-1 and ML-20 cells was inhibited in $E_{2}$-depleted fetal 
bovine serum (FBS), which mimics the status after treatment with an aromatase inhibitor (17).

Oral fluoropyrimidine S-1 contains tegafur in combination with gimeracil (a potent inhibitor of 5-FU degradation) and potassium oxonate at a molar ratio of 1 : 0.4 : 1 ; the combination has lower gastrointestinal toxicity by blocking $5-\mathrm{FU}$ activation in the gastrointestinal tract $(18,19)$. S-1 is considered beneficial and is approved as a clinical therapy for gastric (20), breast (21) and other solid tumor types in over 40 countries. S-1 potentiates the antitumor activity of anastrozole in vitro as observed using an aromatasetransfected, ER-positive human breast cancer cell line, and in vivo (22). In addition to aromatase inhibitors, the specific ER down-regulator fulvestrant (23) is approved for menopausal patients with hormone-responsive breast cancer (24-26). However, studies on combination therapies consisting of fulvestrant and other chemotherapeutics are limited. In this study, we aimed to evaluate a new chemoendocrine therapy using S-1 in combination with fulvestrant.

\section{Patients and Methods}

Chemicals. Tegafur, gimeracil, and potassium oxonate were obtained from Taiho Pharmaceutical Co., Ltd. (Tokyo, Japan). Fulvestrant was purchased from Funakoshi Co., Ltd. (Tokyo, Japan). $\mathrm{E}_{2}$, Dulbecco's modified Eagle's medium/Ham's F-12 (1:1) and FBS were purchased from Sigma-Aldrich Japan (Tokyo, Japan). SE-121 pellet, which contained $0.025 \mathrm{mg} \mathrm{E}_{2} /$ pellet for a 60-day release period, was obtained from Innovative Research of America (Sarasota, FL, USA). Hydroxypropyl methylcellulose was purchased from Shin-Etsu Chemical Co., Ltd. (Tokyo, Japan). 5-FU, peanut oil, dimethyl sulfoxide (DMSO), and crystal violet were purchased from FUJIFILM Wako Pure Chemical Corporation (Osaka, Japan). All other reagents were commercially available products of the highest grade.

Antibodies. Rabbit monoclonal antibodies to human ER $\alpha$ (ab16660, Clone SP1) and human progesterone receptor (PgR) (ab16661, Clone SP2) were purchased from Abnova Japan KK (Tokyo, Japan). Horseradish peroxidase-conjugated goat anti-rabbit IgG Fab fragment HistostarTM $(\mathrm{Rb})$ for mouse tissue analysis was purchased from Medical \& Biological Laboratories Co., Ltd. (Nagoya, Japan) and used for immunohistochemical (IHC) staining.

In vitro cell culture and growth inhibition testing. ER-positive human breast cancer cell line MCF-7, originally obtained from the American Tissue Culture Collection (ATCC, Rockville, MD, USA), was kindly provided by the Osaka University Graduate School of Medicine (Osaka, Japan) and ER-negative human breast cancer cell line MDA-MB-231 was purchased from the ATCC. MCF-7 was cultured using DMEM/Ham's F-12 (1:1) supplemented with $0.1 \mathrm{nM}$ $\mathrm{E}_{2}, 10 \%$ FBS and Glutamax ${ }^{\mathrm{TM}}$ (Life Technologies Japan Ltd, Tokyo, Japan). MDA-MB-231 was cultured using RPMI-1640 supplemented with $10 \% \mathrm{FBS}$ at $37^{\circ} \mathrm{C}$ with $5 \% \mathrm{CO}_{2}$. Cells were collected using TrypLETM Express (Life Technologies Japan Ltd, Tokyo, Japan) and seeded into 96-well plates at a density of 3,000 cells/well on day 0 . The in vitro $\mathrm{E}_{2}$ concentration was equivalent to the serum level in mice achieved by administering the $E_{2}$ pellet based on our previous experiment (data not shown). Fulvestrant and 5-FU were dissolved in DMSO and diluted with culture medium on day 1. The final DMSO concentration was less than $0.5 \%$. Cell growth rates were determined colorimetrically on day 6 by crystal violet staining according to the method reported by Saotome et al. (27). The concentration inhibiting cell growth by $50 \%\left(\mathrm{IC}_{50}\right)$ was calculated by regression analysis.

Interactions between 5-FU and fulvestrant against $\mathrm{MCF}-7$ cells were analyzed using the isobologram method (28). The dose-response curves for treatment with 5-FU and fulvestrant alone were used to derive three isoeffect curves (Mode I, IIa, and IIb), which were analyzed in relation to the $\mathrm{IC}_{50}$ values. The areas enclosed by the three isoeffect curves shown in Figure 2 indicate the envelope. The data points located within the envelope represent additive effects, and data points below the envelope represent supra-additive effects.

In vivo antitumor activity. Five-week-old female BALB/cAJcl nu/nu mice were purchased from CLEA Japan Inc. (Tokyo, Japan) and housed under specific pathogen-free conditions; food and water were provided ad libitum. After the animals had been in quarantine for 5 days, SE- 121 pellet $\left(0.025 \mathrm{mg} \mathrm{E}_{2} /\right.$ pellet $)$ was implanted into the left flank subcutaneously. Because high $\mathrm{E}_{2}$ doses were found to be associated with high mortality in mice due to renal toxicity in a preliminary experiment, one pellet containing $0.025 \mathrm{mg} \mathrm{E}_{2}$ per animal was identified as the optimal amount (data not shown).

One week after the procedure, $\mathrm{MCF}-7$ cells suspended in saline were injected in the right axillary subcutaneously at a dose of $4 \times 10^{6}$ cells per mouse. To evaluate the antitumor activity, the mice were randomized according to tumor volume once the mean tumor volume reached approximately $38-46 \mathrm{~mm}^{3}$ (day 0). Each group consisted of seven mice. One group of mice with no tumor- and SE121-pellet-free was used as negative control $(n=7)$.

S-1 was prepared by mixing tegafur, gimeracil, and potassium oxonate at a molar ratio of 1:0.4:1 in $0.5 \%$ hydroxypropyl methylcellulose. S-1 was administered orally at the reported effective dose $(10 \mathrm{mg} / \mathrm{kg}$, at $10 \mathrm{ml} / \mathrm{kg})$ (18) once daily for 18 consecutive days. Fulvestrant was dissolved in peanut oil and administered into the left femor subcutaneously on day 1 at a dose of $5 \mathrm{mg}$ in $50 \mu \mathrm{l}$ per animal.

The tumor diameters were measured twice a week until day 18 , the last day of administration, and the tumor volume was estimated using the formula $0.5 \times$ length $\times$ width $^{2}$.

All the animal studies were performed according to the guidelines of and approved by the Institutional Animal Care and Use Committee at Taiho Pharmaceutical Co., Ltd. (Approval Number: 17PB06).

IHC staining of ER $\alpha$ and $P g R$. To perform the IHC staining on mouse tissue, tumors were excised on day 19, the day after the last S-1 administration, fixed in 10\% phosphate-buffered formaldehyde ( $\mathrm{pH}$ 7.4) for 1 day followed by the preparation of paraffinembedded tissue sections according to the conventional method. Heat-induced antigen retrieval was applied using a pressure cooker at $121^{\circ} \mathrm{C}$ for $5 \mathrm{~min}$ in Tris-Borate-EDTA buffer (Takara Bio Inc., Kusatsu, Japan) at $\mathrm{pH}$ 8.3. Endogenous peroxidase was inactivated by incubation with $3 \%$ hydrogen peroxide in methanol for $10 \mathrm{~min}$ at room temperature. $\mathrm{ER} \alpha$ and $\mathrm{PgR}$ were detected using rabbit monoclonal anti-human ER $\alpha$ (1:200 dilution) and anti-human PgR (1: 100 dilution) as primary antibodies, respectively. Horseradish 

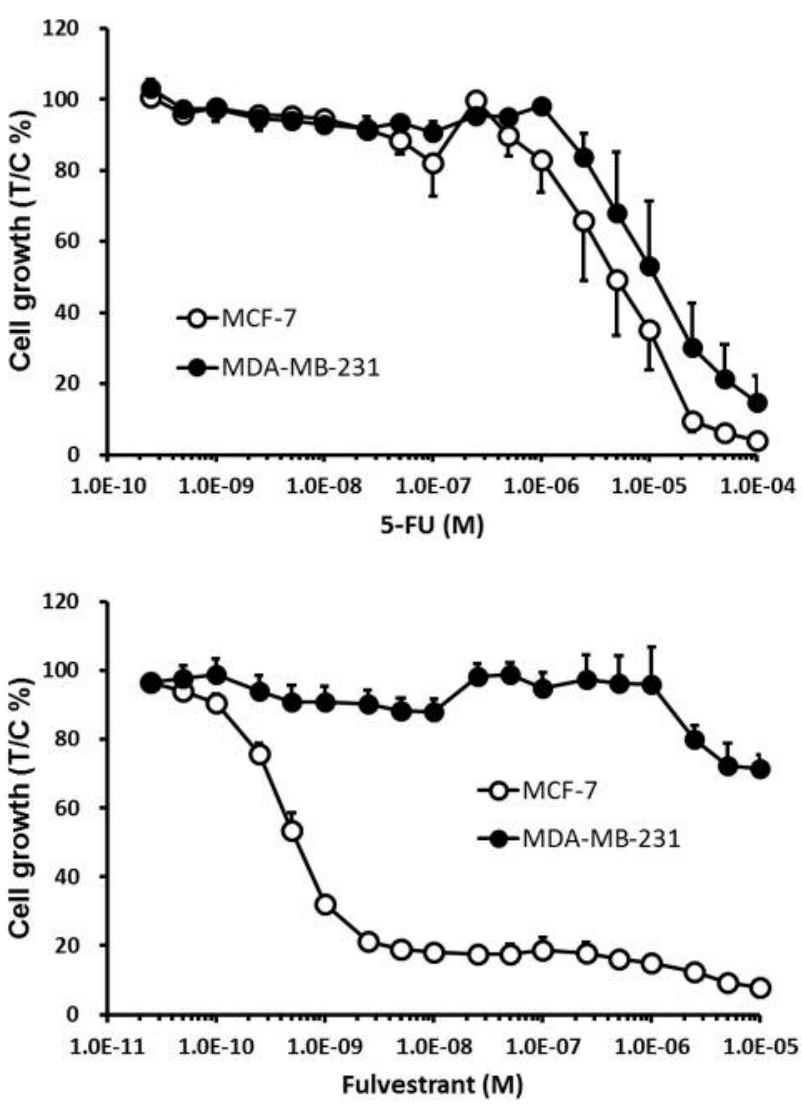

Figure 1. Growth inhibition by single-drug treatment. 5-Fluorouracil (5$F U)(A)$ and fulvestrant $(B)$ were tested for growth inhibition of estrogen receptor (ER)-positive human breast cancer cell line MCF-7 and ERnegative human breast cancer cell line MDA-MB-231 in the presence of $0.1 \mathrm{nM}$ estradiol. The values are the means and $S D$ of cell growth relative to that of the controI $(T / C)$ from three independent experiments.

peroxidase-conjugated goat anti-rabbit antibody for mouse tissue was used as secondary antibody, and a 3, 3'-diaminobenzidine tetrahydrochloride solution containing $0.003 \%$ hydrogen peroxide was added as the substrate followed by Mayer's hematoxylin solution added as counterstain.

Negative control samples were processed without applying the primary antibodies. Three fields of each sample were randomly selected for qualitative analysis without using an unblinded procedure; three slides were evaluated for each treatment group. Approximately, 300 cells/field were counted at a magnification of $400 \times$, except in the necrotic area of the central tumor and the connective tissues or blood vessels.

Statistical analysis. The significance of the differences in the mean tumor volume between the treated and control groups on day 14 was analyzed using the Dunnett's test. The combinational effect of S-1 and fulvestrant was analyzed according to the closed testing procedure using the Aspin-Welch two-tailed $t$-test (29). The significance of the differences in the mean uterine weight on day 1

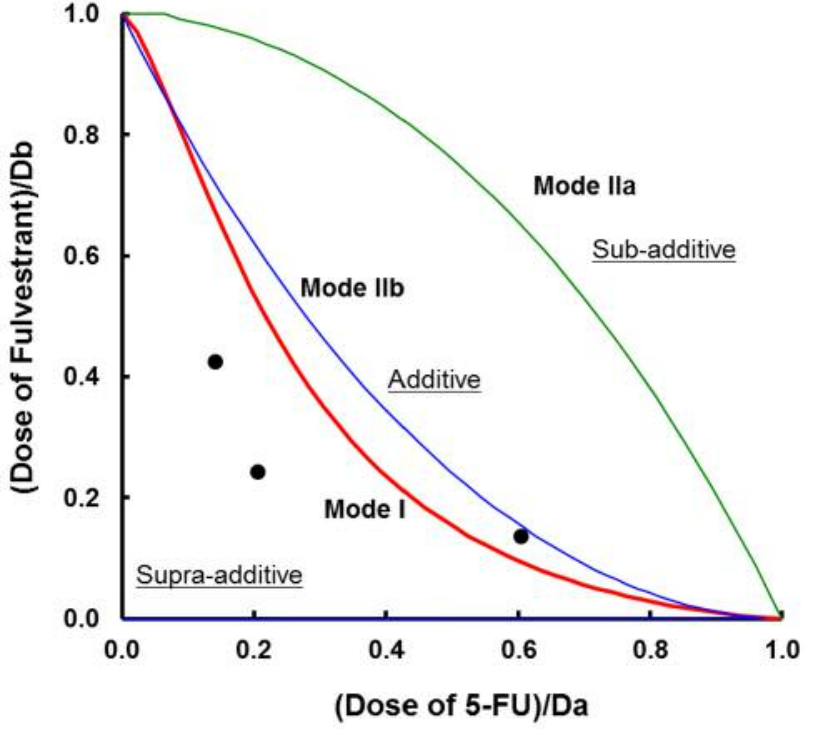

Figure 2. An isobologram curve for the combination treatment with 5-fluorouracil (5-FU) and fulvestrant. Da and $\mathrm{Db}$ indicate the ratio of the concentration inhibiting cell growth by $50 \%\left(I C_{50}\right)$ for 5-FU and fulvestrant in combination therapy to monotherapy, respectively. An envelope of additivity is enclosed by mode I, IIa, and IIb. Data points within the envelope of interaction between 5-FU and fulvestrant indicate additivity, whereas data points below the envelope indicate synergy.

was analyzed using the Aspin-Welch two-tailed t-test. The statistical analyses were performed using EXSAS, Ver. 7.11 (Arm Systex Co., Ltd., Osaka, Japan).

\section{Results}

In-vitro growth inhibition. The single-drug treatment with chemotherapeutic agent 5-FU inhibited the growth of both ER-positive MCF-7 and ER-negative MDA-MB-231 cells in a dose-dependent manner (Figure 1A). Fulvestrant alone inhibited the growth of MCF-7 cells but not of MDA-MB231 cells (Figure 1B). The $\mathrm{IC}_{50}$ values of 5-FU for MCF-7 and MDA-MB-231 were 4.6 and $12.0 \mu \mathrm{M}$, respectively, and their ratio was 2.6 , whereas the respective $\mathrm{IC}_{50}$ values of fulvestrant were $0.8 \mathrm{nM}$ and $>1 \mu \mathrm{M}$ and their ratio was $>12,500$.

In this study, the efficacy of the combination therapy using 5-FU and fulvestrant was assessed in MCF-7 cells. Interestingly, the isobologram data points for the combination therapy of MCF-7 cells were located either within the envelope of additivity or below the envelope, indicating supra-additive effects (Figure 2). Hence, the combination of 5-FU and fulvestrant appears to have a beneficial effect. 




Figure 3. Tumor volume of MCF-7 xenograft in vivo. Nude mice bearing $M C F-7$ xenograft were randomized into four groups $(n=7)$ on day 0 , which was 7 days after the SE-121 pellet (containing $0.025 \mathrm{mg}$ estradiol for 60 days release) had been subcutaneously implanted. Fulvestrant (5 mg/mouse) was administered subcutaneously on day one, $S-1$ $(10 \mathrm{mg} / \mathrm{kg}$ ) was administered orally once daily from day 1 to 18 . Tumor volume was measured twice a week until day 19. The values are the means and SD of tumor volume ( $n=7)$. Significantly different on day 15 at ${ }^{* * *} p<0.001$ vs. control by Dunnett's test; ${ }^{\#} p<0.05 v s$. either monotherapy by Aspin-Welch t-test.

In vivo antitumor activity. As shown in Figure 3, tumor volume reached a plateau on day 15; therefore, S-1 administration was terminated on day 18 , and antitumor effects were evaluated based on the tumor volume on day 14 . Importantly, tumor growth was significantly inhibited by S-1 or fulvestrant $(p<0.001)$. The tumor volume in the combination therapy group was significantly $(p<0.05)$ lower as compared to that in both monotherapy groups. Body weight loss was not observed during the experiment (data not shown).

Table I shows the uterine weight in mice without and with implanted SE-121 pellet containing $0.025 \mathrm{mg} \mathrm{E}_{2}$ that were either treated or not treated with fulvestrant. The SE-121 pellet significantly $(p<0.05)$ increased the uterine weight, and this increase was completely inhibited by concomitant fulvestrant treatment $(p<0.01)$ according to the Aspin-Welch $t$-test.

IHC analysis of ER- $\alpha$ and $P g R$. ER $\alpha$ and $\mathrm{PgR}$ were detected in the MCF-7 xenografts by IHC staining. The intensity and proportion of staining for ER $\alpha$ was partially reduced by fulvestrant, whereas S-1 alone did not appear to affect ER $\alpha$ staining. However, the combination therapy significantly reduced the intensity and proportion of cells staining for $\mathrm{ER} \alpha$ as compared to that of both monotherapies. PgR
Table I. Weight of uterus in nude mice (mean $\pm S D$ ).

\begin{tabular}{lccc}
\hline Treatment & Uterine weight $(\mathrm{g})$ & $\mathrm{n}$ & $p$-Value* \\
\hline SE-121 and tumor-free & $0.066 \pm 0.009$ & 8 & \\
SE-121 alone & $0.097 \pm 0.031$ & 7 & $<0.05^{\mathrm{a}}$ \\
Fulvestrant and SE-121 & $0.035 \pm 0.010$ & 6 & $<0.01^{\mathrm{b}}$ \\
\hline
\end{tabular}

*Aspin-Welch two-tailed $t$-test. ${ }^{a}$ Versus $\mathrm{SE}-121$ free; ${ }^{\text {versus }}$ SE-121 alone.

expression was barely detectable in the group treated with fulvestrant alone, although ER $\alpha$ expression was only partially reduced, indicating that the ER $\alpha$ transduction signal was reduced (Figure 4).

\section{Discussion}

In vitro combination treatment of estrogen-responsive $\mathrm{MCF}$ 7 breast cancer cells with 5-FU and fulvestrant was associated with additive or supra-additive effects. Combination therapy reduced tumor growth more significantly than either monotherapy, which had a more limited reduction in tumor volume relative to the starting volume. Tumoral ER $\alpha$ expression, which was targeted by fulvestrant, was partially reduced by the treatment with this drug, whereas the combination therapy more significantly reduced the expression of ER $\alpha$ than did each monotherapy. These results appeared to corroborate the synergistic cytotoxic effects of 5FU and fulvestrant observed in vitro.

In our previous report, 4-hydroxytamoxifen and estrogendepleted FBS, which mimics the effect of aromatase inhibitor activity in vitro, were shown to increase the activity of fluoropyrimidine (12, 13). In addition, combination therapy using the aromatase inhibitor anastrozole combined with S-1 or UFT was reported to be superior to both monotherapies (22). Furthermore, fulvestrant has been reported to reduce signaling via ER- $\alpha$ by down-regulating the ER $\alpha$ level. The effects of the S-1/fulvestrant combination on MCF-7, a tumorigenic cell line with ER $\alpha$ expression, were similar to those of other chemo-endocrine therapies using an anti-estrogen (4-hydroxytamoxifen) and an aromatase inhibitor (anastrozole) $(12,13,22)$.

An in vivo analysis of the combination of fulvestrant and 5-FU in MCF-7-bearing nude mice has been already reported by Ogasawara et al. (30); the antitumor activity, 5-FU level, and the effect on tumor-associated mRNA was significantly increased, whereas the tumoral ER $\alpha$ level was reduced as compared to that in the 5-FU monotherapy group (30). Interestingly, these results are corroborated by the data from our study. In a previous study, S-1 treatment significantly reduced tumoral mRNA expression of ER (22). Because fulvestrant down-regulates $\mathrm{ER} \alpha$ protein in tumor by 
Non-treated
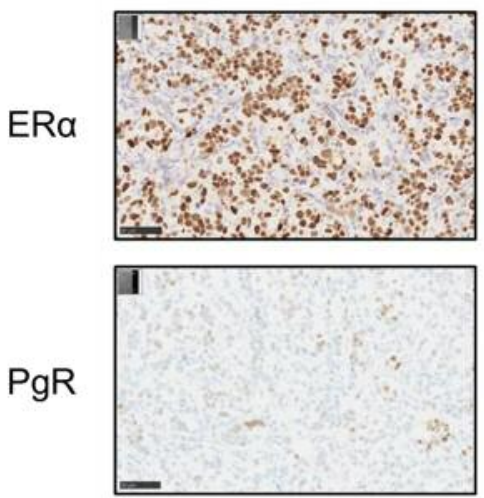
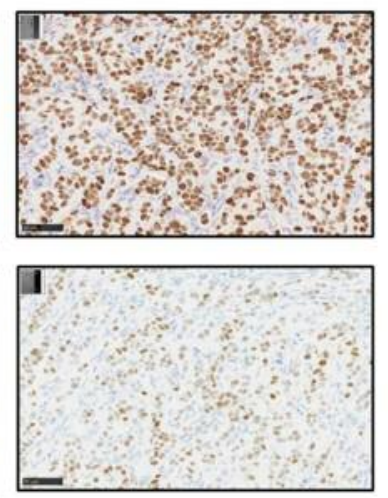

Fulvestrant alone
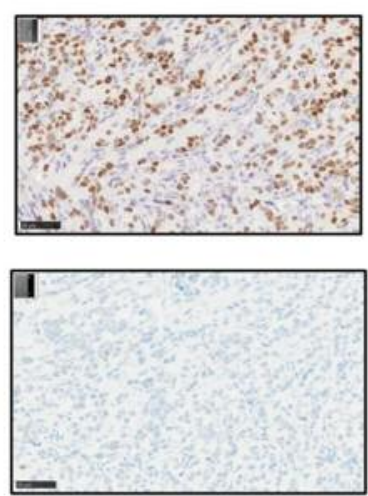

\section{Combination}
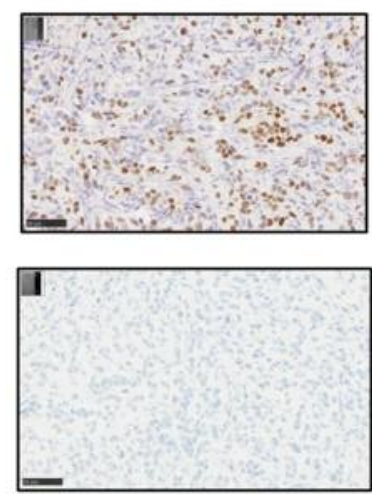

Figure 4. Immunohistochemical staining of estrogen receptor- $\alpha(E R \alpha)$ (upper panel) and progesterone receptor (PgR) (lower panel) in a MCF-7 xenograft subjected to monotherapy with either $S-1$ (10 mg/kg, days $1-18$, orally) or fulvestrant (1 mg/animal, day 1, subcutaneously), or to combination therapy. Tumors were excised on day 19. The bar indicates $100 \mu \mathrm{m}$. The original magnification was 400x.

accelerated degradation and not by suppression of translation/transcription, the addition of S-1 contributed to the down-regulation of ER $\alpha$.

In comparison with other standard chemotherapeutic agents, S-1 has some advantages. Specifically, for longterm treatment, this oral drug appears to be more beneficial than intravenous therapy. Furthermore, an openlabel randomized phase III trial (SELECT BC) demonstrated that S-1 was non-inferior to taxane, a key drug for breast cancer with respect to overall survival, which is used as first-line therapy in metastatic breast cancer and associated with improved quality of life (21). It has been reported that patients with incurable cancer clearly prefer oral chemotherapy as compared to other administration routes if the efficacy is equivalent without reducing the quality of life, which also contributes to better medication adherence (31). The toxicities of S-1 and fulvestrant do not overlap in patients $(19,20,23-25)$. Hair loss is a common adverse effect that severely reduces quality of life, especially for female patients, but the frequency of hair-loss associated with S-1 is low (less than $5 \%$ ) in contrast with other standard chemotherapies, such as taxanes or anthracyclines $(20,32)$.

This study used only MCF-7 cells due to the limited availability of established tumorigenic human breast cancer cell lines which are responsive to estrogen. We also attempted to use T-47D, which is another typical ER-positive human breast cancer cell line, but failed to obtain in vivo growth of T-47D cells in a female nude or SCID mouse model (data not shown). In our current experiment, the maximum $\mathrm{E}_{2}$ dose of $0.025 \mathrm{mg}$, which did not induce renal toxicity, was used. Since this $\mathrm{E}_{2}$ dose significantly increased the uterine weight $(p<0.05)$, it appeared to be adequate for inducing the desired biological activity. However, the mechanism for potentiating ER degradation needs to be investigated further. Future studies should use patientderived xenograft models that are ER-positive to assess the effects of fulvestrant and S-1.

In conclusion, chemo-endocrine therapy using S-1 in combination with fulvestrant may represent a new beneficial candidate therapy for menopausal patients with estrogenresponsive breast cancer that should be evaluated in clinical trials.

\section{Conflicts of Interest}

MN, HS, and TT are employees of Taiho Pharmaceutical Co., Ltd. $\mathrm{SN}$ has been an adviser for and received the honoraria and the research funding related to this study from Taiho Pharmaceutical Co., Ltd. (Tokyo, Japan); SN has also been an adviser for and received the honoraria and the research funding not related to this study from AstraZeneca (Cambridge, UK). This study was funded by Taiho Pharmaceutical Co., Ltd. (Tokyo, Japan). The Authors have no conflict of interest to declare regarding this study.

\section{Authors' Contributions}

$\mathrm{MN}$ and TT planned the experiments. MN is the corresponding Author and wrote the article. HS and MN carried out the experiments. $\mathrm{SN}$ contributed to the interpretation of the results. All Authors provided critical feedback and helped shape the research, analysis, and article.

\section{Acknowledgements}

The Authors would like to thank Editage (www.editage.jp) for English language editing. 


\section{References}

1 Siegel RL, Miller KD and Jemal A: Cancer statistics, 2018. CA Cancer J Clin 68: 7-30, 2018. PMID: 29313949. DOI: 10.3322/ caac. 21442

2 Rugo HS, Rumble RB, Macrae E, Barton DL, Connolly HK, Dickler MN, Fallowfield L, Fowble B, Ingle JN, Jahanzeb M, Johnston SR, Korde LA, Khatcheressian JL, Mehta RS, Muss $\mathrm{HB}$ and Burstein HJ: Endocrine therapy for hormone receptorpositive metastatic breast cancer: American Society of Clinical Oncology guideline. J Clin Oncol 34: 3069-3103, 2016. PMID: 27217461. DOI: $10.1200 /$ JCO.2016.67.1487

3 Vital Statistics Japan (Ministry of Health, Labour and Welfare). Available at: https://ganjoho.jp/reg_stat/statistics/dl/index.html

4 Sonoo H, Kurebayashi J, Iino Y, Inaji H, Watanabe T, Toi M, Kobayashi S, Sato B and Yoshimoto M: Current status and controversial issues concerning endocrine therapy for patients with recurrent breast cancer in Japan. Breast Cancer 6: 344-355, 1999. PMID: 11091741.

5 Loibl S, Turner NC, Ro J, Cristofanilli M, Iwata H, Im SA, Masuda N, Loi S, André F, Harbeck N, Verma S, Folkerd E, Puyana Theall K, Hoffman J, Zhang K, Bartlett CH and Dowsett M: Palbociclib combined with fulvestrant in premenopausal women with advanced breast cancer and prior progression on endocrine therapy: PALOMA-3 results. Oncologist 22: 1028-1038, 2017. PMID: 28652278. DOI: 10.1634/theoncologist. 2017-0072

6 Slamon DJ, Neven P, Chia S, Fasching PA, De Laurentiis M, Im SA, Petrakova K, Bianchi GV, Esteva FJ, Martín M, Nusch A, Sonke GS, De la Cruz-Merino L, Beck JT, Pivot X, Vidam G, Wang Y, Rodriguez Lorenc K, Miller M, Taran T and Jerusalem G: Phase III randomized study of ribociclib and fulvestrant in hormone receptor-positive, human epidermal growth factor receptor 2-negative advanced breast cancer: MONALEESA-3. J Clin Oncol 36: 2465-2472, 2018. PMID: 29860922. DOI: 10.1200/JCO.2018.78.9909

7 Sledge GW Jr., Toi M, Neven P, Sohn J, Inoue K, Pivot X, Burdaeva O, Okera M, Masuda N, Kaufman PA, Koh H, Grischke EM, Frenzel M, Lin Y, Barriga S, Smith IC, Bourayou $\mathrm{N}$ and Llombart-Cussac A: MONARCH 2: Abemaciclib in combination with fulvestrant in women with HR+/HER2advanced breast cancer who had progressed while receiving endocrine therapy. J Clin Oncol 35: 2875-2884, 2017. PMID: 28580882. DOI: $10.1200 /$ JCO.2017.73.7585

8 Krop IE, Mayer IA, Ganju V, Dickler M, Johnston S, Morales S, Yardley DA, Melichar B, Forero-Torres A, Lee SC, de Boer R, Petrakova K, Vallentin S, Perez EA, Piccart M, Ellis M, Winer E, Gendreau S, Derynck M, Lackner M, Levy G, Qiu J, $\mathrm{He} \mathrm{J}$ and Schmid P: Pictilisib for oestrogen receptor-positive, aromatase inhibitor-resistant, advanced or metastatic breast cancer (FERGI): A randomised, double-blind, placebocontrolled, phase 2 trial. Lancet Oncol 17: 811-821, 2016. PMID: 27155741. DOI: 10.1016/S1470-2045(16)00106-6

9 Baselga J, Im SA, Iwata H, Cortés J, De Laurentiis M, Jiang Z, Arteaga CL, Jonat W, Clemons M, Ito Y, Awada A, Chia S, Jagiełło-Gruszfeld A, Pistilli B, Tseng LM, Hurvitz S, Masuda N, Takahashi M, Vuylsteke P, Hachemi S, Dharan B, Di Tomaso E, Urban P, Massacesi C and Campone M: Buparlisib plus fulvestrant versus placebo plus fulvestrant in postmenopausal, hormone receptor-positive, HER2-negative, advanced breast cancer (BELLE-2): A randomised, double-blind, placebo- controlled, phase 3 trial. Lancet Oncol 18: 904-916, 2017. PMID: 28576675. DOI: 10.1016/S1470-2045(17)30376-5

10 Di Leo A, Johnston S, Lee KS, Ciruelos E, Lønning PE, Janni W, O'Regan R, Mouret-Reynier MA, Kalev D, Egle D, Csőszi T, Bordonaro R, Decker T, Tjan-Heijnen VCG, Blau S, Schirone A, Weber D, El-Hashimy M, Dharan B, Sellami D and Bachelot $\mathrm{T}$ : Buparlisib plus fulvestrant in postmenopausal women with hormone-receptor-positive, HER2-negative, advanced breast cancer progressing on or after mTOR inhibition (BELLE-3): A randomised, double-blind, placebo-controlled, phase 3 trial. Lancet Oncol 19: 87-100, 2018. PMID: 29223745. DOI: 10.1016/S1470-2045(17)30688-5

11 Cardoso F, Harbeck N, Fallowfield L, Kyriakides S and Senkus E: ESMO Guidelines Working Group. Locally recurrent or metastatic breast cancer: ESMO Clinical Practice Guidelines for diagnosis, treatment and follow-up. Ann Oncol 23(Suppl 7): vii11-9, 2012. DOI: 10.1093/annonc/mds269.

12 Noguchi S, Koyama H, Uchino J, Abe R, Miura S, Sugimachi $\mathrm{K}$, Akazawa $\mathrm{K}$ and Abe O: Postoperative adjuvant therapy with tamoxifen, tegafur plus uracil, or both in women with nodenegative breast cancer: A pooled analysis of six randomized controlled trials. J Clin Oncol 23: 2172-2184, 2005. PMID: 15800310. DOI: $10.1200 /$ JCO.2005.02.158

13 Ohashi Y, Watanabe T, Sano M, Koyama H, Inaji H and Suzuki T: Efficacy of oral tegafur-uracil (UFT) as adjuvant therapy as compared with classical cyclophosphamide, methotrexate, and 5-fluorouracil (CMF) in early breast cancer: A pooled analysis of two randomized controlled trials (NSAS-BC 01 trial and CUBC trial) Breast Cancer Res Treat 119: 633-641, 2010. PMID: 19936917. DOI: 10.1007/s 10549-009-0635-3

14 Park Y, Okamura K, Mitsuyama S, Saito T, Koh J, Kyono S, Higaki K, Ogita M, Asaga T, Inaji H, Komichi H, Kohno N, Yamazaki K, Tanaka F, Ito T, Nishikawa H, Osaki A, Koyama H and Suzuki T: Uracil-tegafur and tamoxifen $v s$. cyclophosphamide, methotrexate, fluorouracil, and tamoxifen in post-operative adjuvant therapy for stage I, II, or IIIA lymph nodepositive breast cancer: A comparative study. Br J Cancer 101: 598604, 2009. PMID: 19638976. DOI: 10.1038/ sj.bjc.6605218

15 Watanabe T, Sano M, Takashima S, Kitaya T, Tokuda Y, Yoshimoto M, Kohno N, Nakagami K, Iwata H, Shimozuma K, Sonoo H, Tsuda H, Sakamoto G and Ohashi Y: Oral uracil and tegafur compared with classic cyclophosphamide, methotrexate, fluorouracil as postoperative chemotherapy in patients with node-negative, high-risk breast cancer: National Surgical Adjuvant Study for Breast Cancer 01 Trial. J Clin Oncol 27: 1368-1374, 2009. PMID: 19204202. DOI: 10.1200/JCO. 2008.18.3939

16 Kurebayashi J, Nukatsuka M, Nagase H, Nomura T, Hirono M, Yamamoto Y, Sugimoto Y, Oka T and Sonoo H: Additive antitumor effect of concurrent treatment of 4-hydroxy tamoxifen with 5-fluorouracil but not with doxorubicin in estrogen receptor-positive breast cancer cells. Cancer Chemother Pharmacol 59: 515-525, 2007. PMID: 16900372. DOI: 10.1007/ s00280-006-0293-7

17 Kurebayashi J, Nukatsuka M, Sonoo H, Uchida J and Kiniwa M: Preclinical rationale for combined use of endocrine therapy and 5-fluorouracil but neither doxorubicin nor paclitaxel in the treatment of endocrine-responsive breast cancer. Cancer Chemother Pharmacol 65: 219-225, 2010. PMID: 19455332. DOI: $10.1007 / \mathrm{s} 00280-009-1024-7$ 
18 Shirasaka T, Nakano K, Takechi T, Saito H, Okabe H, Oyama $\mathrm{K}$, Takeda S, Unemi N and Fukushima M: Antitumor activity of $1 \mathrm{M}$ tegafur-0.4 M 5-chloro-2,4-dihydroxypyridine-1 M potassium oxonate (S-1) against human colon carcinoma orthotopically implanted into nude rats. Cancer Res 56: 26022606, 1996. PMID: 8653704.

19 Fukushima M, Satake H, Uchida J, Shimamoto Y, Kato T, Takechi T, Okabe H, Fujioka A, Nakano K, Ohshimo H, Takeda $\mathrm{S}$ and Shirasaka T: Preclinical antitumor efficacy of S-1: A new oral formulation of 5-fluorouracil on human tumor xenografts Int J Oncol 13: 693-698, 1998. PMID: 9735397. DOI: 10.3892/ijo.13.4.693

20 Sakuramoto S, Sasako M, Yamaguchi T, Kinoshita T, Fujii M, Nashimoto A, Furukawa H, Nakajima T, Ohashi Y, Imamura H, Higashino M, Yamamura Y, Kurita A and Arai K; ACTS-GC Group: Adjuvant chemotherapy for gastric cancer with S-1, an oral fluoropyrimidine. N Engl J Med 357: 1810-1820, 2007. PMID: 17978289 . DOI: 10.1056/NEJMoa072252

21 Takashima T, Mukai H, Hara F, Matsubara N, Saito T, Takano T, Park Y, Toyama T, Hozumi Y, Tsurutani J, Imoto S, Watanabe T, Sagara Y, Nishimura R, Shimozuma K, Ohashi Y and SELECT BC Study Group: Taxanes versus $\mathrm{S}-1$ as the first-line chemotherapy for metastatic breast cancer (SELECT BC): An open-label, non-inferiority, randomised phase 3 trial. Lancet Oncol 17: 90-98, 2016. PMID: 26617202. DOI: 10.1016/S14702045(15)00411-8

22 Nukatsuka M, Saito H, Nakagawa F, Abe M, Uchida J, Shibata J, Matsuo K, Noguchi S and Kiniwa M: Oral fluoropyrimidine may augment the efficacy of aromatase inhibitor via the downregulation of estrogen receptor in estrogen-responsive breast cancer xenografts. Breast Cancer Res Treat 128: 381-390, 2011 PMID: 20809360. DOI: 10.1007/s10549-010-1141-3

23 Dauvois S, Danielian PS, White R and Parker MG: Antiestrogen ICI 164, 384 reduces cellular estrogen receptor content by increasing its turnover. Proc Natl Acad Sci USA 89: $4037-$ 4041, 1992. PMID: 1570330. DOI: 10.1073/pnas.89.9.4037

24 Wakeling AE, Dukes M and Bowler J: A potent specific pure antiestrogen with clinical potential. Cancer Res 51: 3867-3873, 1991. PMID: 1855205.

25 Osborne CK, Pippen J, Jones SE, Parker LM, Ellis M, Come S, Gertler SZ, May JT, Burton G, Dimery I, Webster A, Morris C, Elledge $\mathrm{R}$ and Buzdar A: Double-blind, randomized trial comparing the efficacy and tolerability of fulvestrant versus anastrozole in postmenopausal women with advanced breast cancer progressing on prior endocrine therapy: Results of a North American trial. J Clin Oncol 20: 3386-3395, 2002. PMID: 12177098. DOI: $10.1200 / J C O .2002 .10 .058$
26 Howell A, Robertson JF, Abram P, Lichinitser MR, Elledge R, Bajetta E, Watanabe T, Morris C, Webster A, Dimery I and Osborne CK: Comparison of fulvestrant versus tamoxifen for the treatment of advanced breast cancer in postmenopausal women previously untreated with endocrine therapy: A multinational, double-blind, randomized trial. J Clin Oncol 22: 1605-1613, 2004. PMID: 15117982. DOI: 10.1200/JCO.2004.02.112

27 Saotome K, Morita H and Umeda M: Cytotoxicity test with simplified crystal violet staining method using microtitre plates and its application to injection drugs. Toxicol In Vitro 3: 317321, 1989. PMID: 20702298.

28 Fivelman QL, Adagu IS and Warhurst DC: Modified fixed-ratio isobologram method for studying in vitro interactions between atovaquone and proguanil or dihydroartemisinin against drugresistant strains of Plasmodium falciparum. Antimicrob Agents Chemother 48: 4097-4102, 2004. PMID: 15504827. DOI: 10.1128/AAC.48.11.4097-4102.2004

29 Bauer P, Röhmel J, Maurer W and Hothorn L: Testing strategies in multi-dose experiments including active control. Stat Med 17: 2133-2146, 1998. PMID: 9789919.

30 Ogasawara Y, Doihara H, Shiroma K, Kanaya Y and Shimizu N: Effects of experimental chemoendocrine therapy with a combination of a pure antiestrogen and 5-fluorouracil on human breast cancer cells implanted in nude mice. Surg Today 29: 149156, 1999. PMID: 10030740. DOI: 10.1007/BF02482240

31 Liu G, Franssen E, Fitch MI and Warner E: Patient preferences for oral versus intravenous palliative chemotherapy. J Clin Oncol 15: 110-115, 1997. PMID: 8996131. DOI: 10.1200/JCO.1997. 15.1.110

32 Nokihara H, Lu S, Mok TSK, Nakagawa K, Yamamoto N, Shi YK, Zhang L, Soo RA, Yang JC, Sugawara S, Nishio M, Takahashi T, Goto K, Chang J, Maemondo M, Ichinose Y, Cheng Y, Lim WT, Morita S and Tamura T: Randomized controlled trial of S-1 versus docetaxel in patients with non-small-cell lung cancer previously treated with platinum-based chemotherapy (East Asia S-1 Trial in Lung Cancer). Ann Oncol 28: 2698-2706, 2017. PMID: 29045553. DOI: $10.1093 /$ annonc/mdx419
Received May 20, 2019

Revised June 21, 2019

Accepted July 4, 2019 